\title{
MAKNA SIMBOLIS TARI RAWAYAN KARYA GUGUM GUMBIRA
}

\author{
Dwi Risnawati Ayuningsih \\ Jurusan Tari Fakultas Seni Pertunjukan Institut Seni Indonesia Yogyakarta \\ Email: dwirisnawatiayuningsih@gmail.com
}

\begin{abstract}
RINGKASAN
Tari Rawayan merupakan tari Jaipongan karya Gugum Gumbira Tirasondjaja yang diciptakan tahun 1986 sebagai hadiah dalam acara memperingati hari ulang tahun Ibu Negara Republik Indonesia yaitu Raden Ayu Siti Hartinah atau yang akrab disapa ibu Tien Soeharto di gedung Sasono Langen Budoyo Taman Mini Indonesia Indah Jakarta. Tari Rawayan merupakan suatu tarian yang berisi wejangan kepada seluruh masyarakat khususnya pada masa pemerintahan bapak Soeharto dan ibu Tien bahwa dalam masa pembangunan yang sedang berlangsung ini, bapak Soeharto dan ibu Tien harus ingat dan hati-hati dalam mempertahankan nilai-nilai tradisi yang dimiliki bangsa Indonesia. Nilai-nilai tradisi tersebut adalah nilai-nilai kehati-hatian dalam bertindak akan segala sesuatu. Penelitian ini memfokuskan pada makna simbolis yang terkandung dalam tari Rawayan. Untuk menjawab permasalahan tersebut digunakan pendekatan hermeneutika dengan teori intensional Weber. Pendekatan hermeneutika membantu peneliti dalam memahami sisi historis dan humanistik dari latar belakang penciptaan tari Rawayan dan sosok Gugum Gumbira dalam menciptakan tari Rawayan. Teori intensional mengungkapkan bahwa makna hadir berdasarkan niat dan tujuan dari sang pencipta tari. Teori tersebut membantu memahami makna tersirat pada tari Rawayan yang terkandung dari berbagai aspek pendukung tari yaitu gerak tari, rias busana, serta iringan tari. Ketiga aspek pendukung tari tersebut menuju pada satu makna yang sama yaitu makna kehati-hatian dalam menjalani kehidupan.
\end{abstract}

Kata Kunci: Gugum Gumbira, Tari Rawayan, Makna simbolis.

\begin{abstract}
Rawayan dance is a Jaipongan dance by Gugum Gumbira Tirasondjaja which was created in 1986 as a gift to commemorate the birthday of the First Lady of the Republic of Indonesia, Raden Ayu Siti Hartinah or familiarly known as Tien Soeharto's in Sasono Langen Budoyo building Beautiful Indonesia Miniature Park Jakarta. Rawayan dance is a dance that contains advice to the entire community, especially during the reign of Mr. Soeharto and Mrs. Tien that in this ongoing development period, Mr. Soeharto and Mrs. Tien must remember and be careful in maintaining the traditional values of the Indonesian people.These traditional values are the values of prudence in acting on everything.

This study focuses on the symbolic meaning contained in Rawayan dance, to answer the problems of the research, a hermeneutic approach is used with the intentional theory put forward by Max Weber. The hermeneutic approach helps researchers to understand the historical and humanistic side of the background of the creation of Rawayan dance and Gugum Gumbira's own figure in creating Rawayan dance. Intentional theory reveals that meaning is present based on the intention and purpose of the creator of dance. The theory helps researchers to understand the implicit meal found in Rawayan dance. The symbolic meaning contained in Rawayan dance can be
\end{abstract}




\section{JOGED}

seen from many aspects of dance support namely dance moves, dressing, and dance accompaniment. Of the three aspects of supporting the dance, headed on one and the same meaning is the meaning of caution in living life.

Key Words: Gugum Gumbira, Rawayan dance, symbolic meaning.

\section{PENDAHULUAN}

Tari Rawayan merupakan sebuah tarian bergenre tari Jaipongan yang diciptakan oleh Gugum Gumbira pada tahun 1986 sebagai hadiah ulang tahun ibu Tien Soeharto di Gedung Sasono Langen Budoyo Taman Mini Indonesia Indah Jakarta dan ditarikan oleh tujuh orang penari putri. Pada bagian tata rias busana tari Rawayan, di bagian rias kepala menggunakan konde (sanggul), hiasan sanggul berbentuk daun awi (daun bambu), dan ronce (rangkaian bunga melati). Pada bagian busana, tari Rawayan menggunakan rompi, baju lengan panjang berbahan ketat, sinjang dodot yang dimodifikasi menjadi rok, dan celana panjang berbahan ketat. Busana tersebut didominasi dengan warna biru tua dan biru muda. Laras gamelan yang mengiringi tari Rawayan adalah laras saléndro dengan Gending Sekar Ageung dalam lagu Tablo Naik Gendu. ${ }^{1}$ Kata Rawayan merupakan bahasa Sunda yang memiliki arti jembatan gantung yang terbuat dari bambu. Jembatan gantung

${ }^{1}$ Iyus Rusliana, Gugum Gumbira Dari ChaCha Ke Jaipongan, Bandung: Sunan Ambu Press - STSI Bandung, 2007, 82. tersebut berada di Kecamatan Leuwidamar, Kabupaten Lebak, Desa Kanekes, Kampung Gajeboh, Banten, Jawa Barat.

Hasil wawancara peneliti dengan Gugum Gumbira, bahwasanya dalam penciptaan tari Rawayan Gugum Gumbira tidak diberikan tema khusus untuk pembuatan karya tari tersebut, namun karena Negara Republik Indonesia saat itu dipimpin oleh bapak Presiden Soeharto dan ibu Tien yang dikenal sebagai bapak dan ibu pembangunan, Gugum Gumbira membuat karya yang sarat akan kehati-hatian. Gugum Gumbira menjelaskan bahwa orang-orang yang mengerti tradisi sangat hati-hati dalam membangun sesuatu entah itu sesuatu yang tampak seperti contohnya sebuah bangunan atau sesuatu yang tidak tampak seperti contohnya karakter atau sebuah pemikiran, begitu juga yang Gugum Gumbira harapkan dari pemahamannya mengenai kehati-hatian 
yang ditujukan untuk bapak dan ibu pembangunan. $^{2}$

Pada tari Rawayan, peneliti tertarik dengan bentuk visual tari Rawayan yang meliputi aspek gerak dan rias busana, selain itu peneliti telah menguasai tari Rawayan sehingga tertarik untuk meneliti latar belakang penciptaan, makna, dan pesan yang ingin disampaikan oleh Gugum Gumbira dalam tari Rawayan tersebut.

\section{PEMBAHASAN}

\section{A. Latar Belakang Penciptaan Tari Rawayan}

Latar Belakang Gugum Gumbira diminta untuk membuat karya tari sebagai hadiah ulang tahun ibu Tien Soeharto dikarenakan Gugum Gumbira memiliki hubungan erat dengan Keluarga Cendana. Hal tersebut dikarenakan para putri dari bapak Soeharto dan ibu Tien belajar tari Jaipongan dengan Gugum Gumbira, yang membuat putri dari bapak Soeharto dan ibu Tien berniat untuk dibuatkan tari Jaipongan sebagai hadiah ulang tahun untuk sang ibunda. Dipilihnya tari Jaipongan dan seorang Gugum Gumbira juga dikarenakan tari Jaipongan sedang ramai dibicarakan sebagai genre baru tari Sunda dan pengalaman seorang Gugum Gumbira dalam

2 Wawancara dengan Gugum Gumbira, pencipta tari Rawayan, tanggal 13 Januari 2019. Diizkan untuk dikutip. membuat karya-karya tari untuk penyambutan dan perayaan hari-hari besar kenegaraan yang ditarikan oleh penari secara kelompok kecil maupun secara kelompok besar atau kolosal.

Pada proses penciptaan tari Rawayan dalam seluruh aspeknya diawasi oleh para istri dari Kabinet Pemerintahan Soeharto yang beretnis Sunda. Mereka bersama-sama ikut berpartisipasi untuk mensukseskan penciptaan tari Rawayan tersebut. Para istri tersebut memberikan masukan dan pesan bahwasanya karya tari Jaipongan ini akan dipentaskan di depan tamu kenegaraan, maka dari itu seluruh unsur koreografi tari Rawayan dibuat sebaik mungkin dengan tetap menghargai seorang ibu Tien Soeharto yang berlatar belakang seorang bangsawan dari Mangkunegaran.

Secara kebetulan, Gugum Gumbira bertemu dengan seorang anggota Suku Baduy Luar yang datang ke kediamannya, sayangnya Gugum Gumbira tidak menjelaskan lebih lanjut mengenai siapa nama orang tersebut, apakah dia masyarakat biasa atau memiliki kedudukan di Suku Baduy Luar, dan apa tujuannya datang ke kediaman Gugum. Orang dari masyarakat Suku Baduy Luar tersebut merceritakan tentang bagaimana nilai-nilai kehidupan tradisional masyarakat Suku Baduy masih dipertahankan hingga saat ini. Cerita tersebut dijadikan inspirasi oleh Gugum Gumbira untuk menciptakan sebuah nama karya tari yang akan dipersembahkan sebagai 


\section{JOGED}

hadiah ulang tahun ibu Tien yaitu Tari Rawayan. Gugum Gumbira mengatakan, beliau ingin menyampaikan kepada bapak Soeharto dan ibu Tien bahwa dalam masa pembangunan yang sedang berlangsung ini, bapak Soeharto dan ibu Tien harus ingat dan hati-hati dalam mempertahankan nilai-nilai tradisi yang dimiliki bangsa Indonesia. Nilainilai tradisi tersebut adalah nilai-nilai kehatihatian dalam bertindak akan segala sesuatu.

Gugum Gumbira sangat detail dalam proses penciptaan tari Rawayan, segala hal sekecil apapun sangat dipertimbangkan, mulai dari aspek gerak, aspek rias busana, suasana dari iringan musik, pemilihan gending, dan syair lagu di dalam tari Rawayan yang dibuat oleh Gugum Gumbira bersama tim penata rias dan busana serta penata iringan tari Rawayan menggunakan makna simbolis yang membantu agar pesan yang ingin disampaikan tercapai, meskipun secara tersirat (implisit). Gugum Gumbira bersikeras untuk membuat karya tari yang tetap bergenre tari Jaipongan namun berbeda dari tari Jaipongan lainnya dan memiliki makna yang dalam namun dapat dipahami, tidak hanya oleh kalangan masyarakat yang mengenal dunia tari namun juga dipahami oleh kalangan masyarakat awam yang tidak mengenal dunia tari.

\section{B. Bentuk Penyajian Tari Rawayan}

\section{Tema Tari Rawayan}

Tema dari tari Rawayan ini adalah kehati-hatian yang meliputi segala aspek kehidupan yang dijalani seorang manusia. Tema tersebut ditafsirkan berdasarkan wawancara peneliti dengan Gugum Gumbira yang ingin menyampaikan kepada bapak Soeharto dan ibu Tien bahwa dalam masa pembangunan yang sedang berlangsung, bapak Soeharto dan ibu Tien harus ingat dan hati-hati dalam mempertahankan nilai-nilai tradisi yang dimiliki bangsa Indonesia. Nilai-nilai tradisi tersebut adalah nilai-nilai kehati-hatian dalam bersikap, berbicara, dan bertindak akan segala sesuatu.

\section{Judul Tari Rawayan}

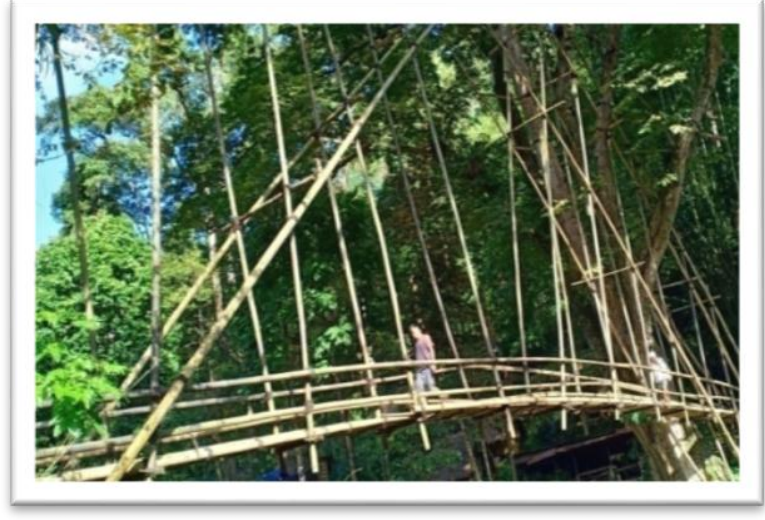

Gambar 1: Rawayan yang Menghubungkan Kampung Gajeboh dan Kampung Cicakal Muara.

Sumber: Dokumentasi Dwi Risnawati Ayuningsih, tanggal 30 Maret 2019.

Judul pada karya tari Rawayan ini diambil dari kata rawayan yang berasal dari bahasa Sunda yang memiliki arti jembatan gantung yang terbuat dari bambu. Jembatan 
yang dimaksud dalam judul karya tari Rawayan merupakan jembatan gantung yang terdapat di Kampung Gajeboh, Desa Kanekes, Kabupaten Lebak, Banten, Jawa Barat. Korelasi antara judul tari dengan tema tari Rawayan adalah disaat menyeberangi rawayan, kita harus berhati-hati dalam melangkah. Hal tersebut dianalogikan dengan situasi yang terjadi pada masa pembangunan yang dipimpin bapak Soeharto dan ibu Tien. Gugum Gumbira ingin menyampaikan kepada bapak Soeharto dan ibu Tien bahwa dalam masa pembangunan yang sedang berlangsung ini, bapak Soeharto dan ibu Tien harus ingat dan hati-hati dalam mempertahankan nilainilai tradisi yang dimiliki bangsa Indonesia agar tercapai kestabilan yang merupakan persyaratan agar pembangunan dapat berlangsung dengan baik. ${ }^{3}$

\section{Aspek Gerak Tari Rawayan}

Gerak pada tari Rawayan terinspirasi oleh gerak-gerak Ketuk Tilu dan Pencak Silat. Pada aspek gerak tari Rawayan memiliki tipikal gerak yang khas dalam menggerakkan setiap frase dan motifnya. Setiap desain-desain gerak yang terdapat pada tari Rawayan berjangkauan luas, lebar, panjang dan tinggi dengan ritme lambat namun dapat berubah menjadi tiba-tiba cepat. Tari Rawayan

3 Wawancara dengan narasumber Gugum Gumbira, pencipta tari Rawayan, tanggal 13 Januari 2019. Diizkan untuk dikutip. memiliki tiga frase gerak spesifik yaitu Lengkah Maung, Bata Murag, dan Teundeut Jagat yang tidak ditemukan di tari Jaipongan lain dan juga tidak tampak unsur 3G (Geol, Gitek, Goyang) pada gerak tarinya.

Peniadaan unsur gerak 3G (Geol, Gitek, Goyang) yang menjadi ciri khas tari Jaipongan dilakukan sebagai wujud menghargai latar belakang ibu Tien Soeharto sebagai perempuan Jawa yang masih memiliki keturunan darah Mangkunegaran, karena unsur 3G (Geol, Gitek, Goyang) di daerah Jawa Tengah dianggap sebagai hal yang mengarah ke pada sesuatu yang dalam bahasa Jawa disebut saru dan memiliki arti tidak senonoh. Unsur 3G (Geol, Gitek, Goyang) tersebut juga ditiadakan mengingat tari Rawayan ini dipentaskan di hadapan para pemimpin negara dan dihadiri oleh para tamu-tamu undangan kenegaraan dalam acara memperingati hari ulang tahun Ibu Negara Republik Indonesia. Hal tersebut menjadikan tari Rawayan sebagai pelopor pembaharuan tari Jaipongan dan mengubah citra tari Jaipongan yang terkesan erotis menjadi tari yang patut disejajarkan dengan genre tari Sunda sebelumnya yang bergenre tari klasik.

Tari Rawayan memiliki gerak spesifik yang hanya ada pada tari Rawayan, gerakan tersebut adalah frase gerak Lengkah Maung, Bata Murag, dan Teundeut Jagat. Lengkah Maung merupakan bahasa Sunda yang berarti 


\section{JOGED}

langkah harimau. Masyarakat Sunda menggunakan harimau sebagai simbol dalam berbagai hal seperti penggunaan nama daerah (Cimacan), simbol Komando Daerah Militer (Kodam) Siliwangi, hingga julukan klub sepak bola kebanggaan warga Bandung (Persib) yang dijuluki Maung Bandung. Simbol maung digunakan masyarakat Sunda sebagai pedoman hidup bahwa sifat-sifat harimau seperti pemberani, tegas, namun sangat menyayangi keluarga sebagai lelaku yang harus dijalani dalam kehidupan nyata. ${ }^{4}$

Bila dilihat dari gerakan dan pemilihan nama gerak dapat dikatakan bahwa Gugum Gumbira terinspirasi dari cara berjalan harimau sang raja hutan yang tangguh dan percaya diri namun tetap berhati-hati menjaga langkahnya bila mana terjadi serangan. Gugum Gumbira menganalogikan sifat binatang harimau dengan sifat seorang raja atau pemimpin, penguasa, panutan yang pemberani, tegas, namun sangat menyayangi keluarga.

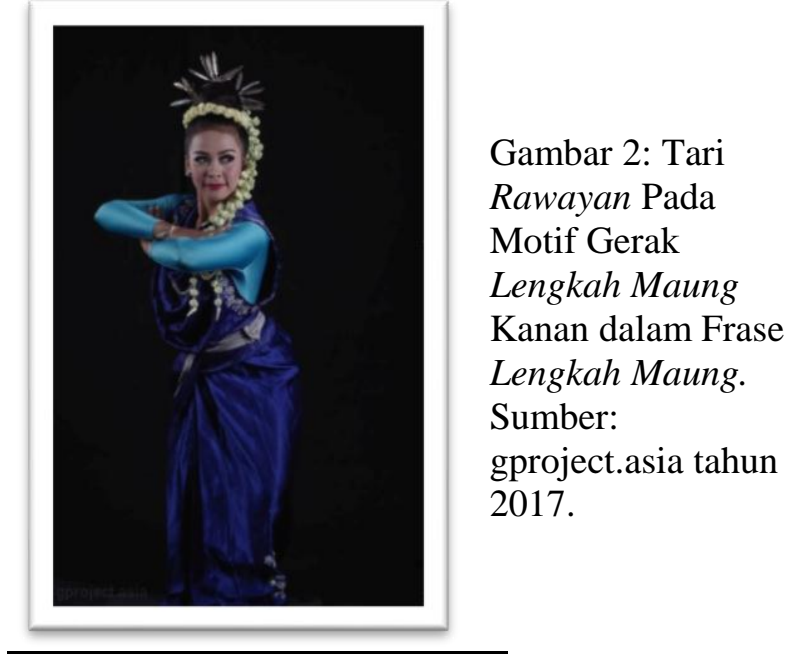

4 www.berdikarionline.com diakses pada tanggal 11 Mei 2019 pada pukul 20.42 WIB.
Pada saat melakukan frase gerak Lengkah Maung, keseimbangan kaki penari harus dijaga dengan baik, karena bila tidak menjaga keseimbangan dalam melakukan geraknya penari akan mudah terjatuh. Hal tersebut Gugum Gumbira analogikan dengan kehidupan manusia, saat menjalani kehidupan, manusia harus berhati-hati dalam mengambil langkah, tindakan, keputusan, dan sebagainya agar tidak terjadi hal-hal yang buruk menimpanya.

Bata Murag merupakan bahasa Sunda yang berarti bata atau sejenis batu untuk membangun bangunan yang jatuh. Gugum Gumbira menganalogikan bata yang jatuh tersebut dengan suatu kejadian yang menakutkan atau mengerikan yang dapat terjadi di dalam kehidupan manusia. Kejadian tersebut dapat berupa kehilangan dengan contoh kehilangan orang yang dicintai, kehilangan harta benda, kehilangan derajat dan martabat, dan jenis kehilangan yang lainnya.

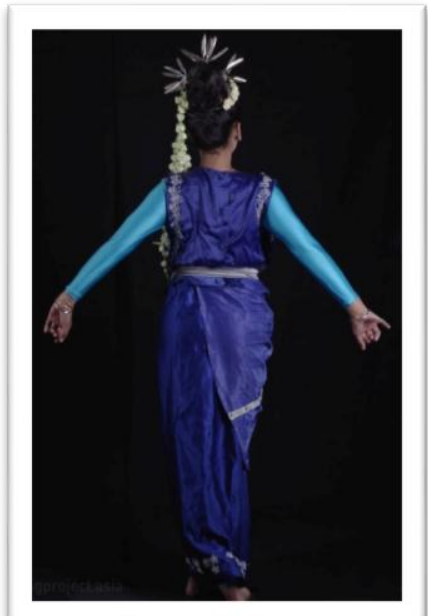

Gambar 3: Tari

Rawayan pada Motif Gerak Malik Lengah Dalam Frase Bata Murag.

Sumber: gproject.asia tahun 2017. 
Pada saat melakukan frase gerak Bata Murag, keseimbangan kaki dan keluwesan torso penari harus dilakukan dengan baik, karena bila tidak memiliki keseimbangan dan keluwesan dalam bergerak penari akan mudah terjatuh dan terkilir. Hal tersebut Gugum Gumbira analogikan dengan kehidupan manusia, yang harus siap dalam segala kondisi disaat menjalani kehidupan dan memiliki hati yang lapang saat tertimpa musibah. Manusia harus berhati-hati dalam mengambil langkah, tindakan, keputusan, dan sebagainya agar tidak terjadi hal-hal yang buruk menimpanya, namun bila hal buruk itu terjadi maka kita harus sabar menjalaninya dan berdoa agar kita dapat bangkit dari keterpurukan tersebut.

Teundeut Jagat merupakan bahasa Sunda yang berarti menekan semesta. Gugum Gumbira menganalogikan menekan semesta dengan membuat suatu keputusan dengan segala pertimbangan untuk sebuah kebaikan. Setiap manusia dalam menjalani kehidupannya pasti selalu dihadapkan dengan berbagai pilihan. Terkadang manusia menjadi bimbang untuk mengambil keputusan mana yang paling baik. Manusia memerlukan tekad dan keyakinan yang kuat untuk percaya mengambil sebuah keputusan. Kebulatan tekad dan keyakinan bahwa keputusan yang dipilih itu tepat akan membawa kita pada kebaikan itu sendiri.

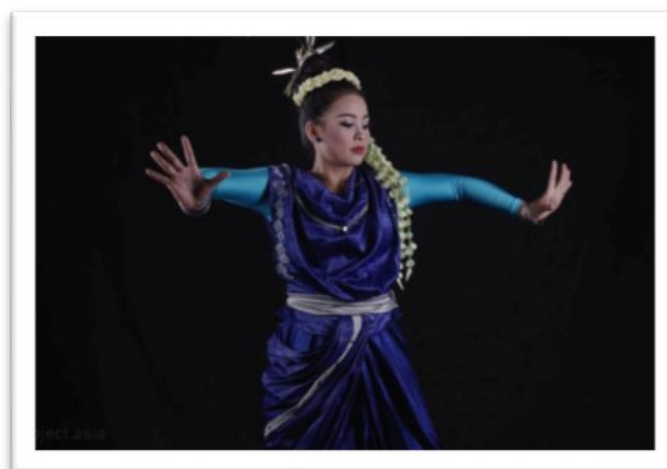

Gambar 4: Tari Rawayan pada Motif Gerak Teundeut Jagat dalam Frase Teundeut Jagat. Sumber: gproject.asia tahun 2017.

Pada saat melakukan frase gerak Teundeut Jagat, dibutuhkan keluwesan pada bagian torso, jangkauan tangan yang luas, dan keseimbangan yang baik, karena bila tidak memiliki keluwesan, jangkauan tangan yang luas dan keseimbangan dalam bergerak penari akan mudah terjatuh, terkilir, dan gerakan tersebut tampak tidak tuntas digerakkan. Hal tersebut Gugum Gumbira analogikan dengan kehidupan manusia, yang harus memiliki sikap yang luwes dalam segala keadaan namun tetap mempunyai satu tujuan dan meyakini tujuan tersebut adalah yang terbaik.

\section{Aspek Penari dalam Tari Rawayan}

Hasil wawancara peneliti dengan Mira Tejaningrum selaku putri dari Gugum Gumbira dan salah satu penari pertama yang menarikan tari Rawayan mengatakan bahwa tari Rawayan pertama kali ditarikan oleh tujuh orang penari perempuan. Tujuh penari perempuan tersebut bernama Mira, Nani, Nina, 


\section{JOGED}

Cica, Yayah, Ine, dan Iin. Tari Rawayan ditarikan oleh penari berjenis kelamin perempuan karena menurut Gugum Gumbira perempuan memiliki sifat lembut namun terlihat kokoh dan kuat yang berbeda dengan laki-laki. ${ }^{5}$

Sebagian besar karya-karya tari Jaipongan Gugum Gumbira ditarikan oleh penari perempuan. Gugum Gumbira terinspirasi oleh penari perempuan pada kesenian Ketuk Tilu dan Kliningan Bajidoran yang disebut ronggeng. Gugum Gumbira memandang ronggeng bukan hanya sebatas sosok perempuan pemuas hasrat bajidor (penari laki-laki yang ada di kesenian Kliningan Bajidoran) tetapi juga sosok perempuan yang memiliki rasa juang dan rasa kepercayaan diri yang tinggi dalam mempertahankan hidup demi keluarganya. Pada koreografi tari Rawayan memiliki banyak motif langkah beritme lambat dengan pengaturan tenaga yang halus namun terlihat kokoh dan kuat. Rasa halus namun kokoh tersebutlah yang merupakan sebuah keindahan yang hanya dimiliki oleh perempuan menurut Gugum Gumbira. ${ }^{6}$

Kriteria kepenarian yang menjadi tolak ukur kemampuan penari Sunda yaitu bisa,

${ }^{5}$ Wawancara dengan Mira Tejaningrum, putri dari Gugum Gumbira dan penari tari Rawayan, tanggal 13 April, 2019. Diizinkan untuk dikutip.

6 Wawancara dengan Gugum Gumbira, pencipta tari Rawayan, tanggal 12 Januari 2019. Diizinkan untuk dikutip. wanda, wirahma, sari, dan alus. Bisa, adalah tingkat kepiawaian penguasaan gerak atau koreografi. Wanda, adalah tingkat kepiawaian penyelarasan postur tubuh, rias, dan busana dengan tarian yang dibawakan. Wirahma, adalah tingkat kepiawaian penguasaan irama tari dan keselarasan dengan iringan tari. Sari, adalah tingkat kepiawaian penguasaan isi tarian atau penjiwaan. Alus, adalah tingkat kepiawaian penguasaan menyatukan kekuatan unsur bisa, wanda, wirahma, dan sari. Pada tahap pemilihan penari yang menarikan tari Rawayan, Gugum Gumbira memilih penari yang memiliki kriteria alus. Penari yang menarikan tari Rawayan harus berkriteria alus karena dalam tari Rawayan Gugum Gumbira memberikan makna yang dalam. Gugum Gumbira ingin penarinya piawai menyelaraskan unsur gerak, iringan tari, rias busana, dan penjiwaan pada tari Rawayan.

\section{Aspek Iringan Tari Rawayan}

Hasil wawancara dengan Ismet Ruchimat selaku arranger iringan tari Rawayan disimpulkan bahwa pada awalnya di tahun 1986 kreator iringan tari Rawayan adalah bapak Meman dan kawan-kawan. Ismet mengaransemen iringan tari Rawayan pada tahun 2013. Alasan Padepokan Jugala mengaransemen iringan tari Rawayan adalah sebagai wujud pembaharuan. Tidak ada hal yang diubah dalam aransemen yang dilakukan 
oleh Ismet, Ismet hanya menambah kualitas iringan tanpa mengubah struktur dan pola musik iringan tari Rawayan terdahulu. Pada penjelasannya Ismet menambahkan, iringan musik tari Rawayan memiliki banyak keunikan yang tidak dimiliki oleh iringan tari Jaipongan lain.

Keunikan yang dimiliki adalah iringan tari Rawayan merupakan pelopor tepak kendang progresif karena cara memainkan kendangnya tidak verbal mengikuti gerak tarinya atau bersifat kontras dengan gerak penari, pemain alat musiknya mengerti estetika musik karena memiliki latar belakang akademis, rumpaka (lirik lagu) yang mengiringi tari Rawayan diambil dari rumpaka pupuh (lirik puisi) dari pupuh Asmarandana yang menceritakan tentang pepeling (pengingat), serta iringan tarinya menggunakan Gending Sekar Ageung dengan lagu Tablo Naik Gendu. Baik iringan maupun gerak tari Rawayan merupakan master piece dari Padepokan Jugala. ${ }^{7}$ Bentuk gending yang mengiringi tari Rawayan adalah Gending Sekar Ageung. Gending Sekar Ageung dapat juga disebut lagu ageung atau lagu besar yang gendingnya relatif panjang dan suasana yang dimunculkan oleh suaranya adalah keteguhan hati dan kasmaran. Biasanya Gending Sekar Ageung digunakan untuk mengiringi tarian

7 Wawancara dengan Ismet Ruchimat ,arranger tari Rawayan pada tahun 2013, tanggal 2 April 2019. Diizinkan untuk dikutip. bergenre Wayang, namun Meman dan Gugum Gumbira memakai Gending Sekar Ageung untuk memberikan suasana keagungan pada tari Rawayan ini. Alasan pemilihan Gending Sekar Ageung karena gending tersebut memiliki suasana yang agung dan hikmat. Suasana tersebut dibangun sebagai wujud penghormatan kepada bapak Soeharto dan ibu Tien sebagai sosok pemimpin Negara Republik Indonesia beserta tamu-tamu undangan kenegaraan, dengan harapan dapat menjadi hadiah yang pantas dan dapat menyenangkan hati serta sebagai sambutan yang hangat bagi bapak Soeharto, ibu Tien, dan masyarakat lain yang menonton. ${ }^{8}$ Rumpaka (lirik lagu) yang mengiri tari Rawayan diambil dari rumpaka pupuh (lirik puisi) dari pupuh Asmarandana dan rumpaka Tablo Naik Gendu yang dibuat sendiri oleh Gugum Gumbira bersama Meman dan kawankawan. ${ }^{9}$ Isi rumpaka tersebut menceritakan tentang pepeling (pengingat) bagi manusia yang hidup di dunia.

Arti syair lagu tari Rawayan ini mengingatkan kita sebagai manusia bahwa hidup di dunia ini hanya sementara, kita pun tidak memiliki kekuasaan, dan bila kita menyimpang penyesalanlah yang akan kita

8 Wawancara dengan Gugum Gumbira, pencipta tari Rawayan, tanggal 13 Januari 2019. Diizkan untuk dikutip.

${ }^{9}$ Wawancara dengan Asep Saepudin, dosen Jurusan Karawitan ISI Yogyakarta, tanggal 24 April 2019. Diizinkan untuk dikutip. 


\section{JOGED}

dapatkan. Jika kita sayang pada diri kita sendiri, sudah tentu kita tidak punya sifat dengki yang ada di dalam hidup. Dunia ini memiliki banyak kebahagiaan, maka dari itu kita sesama manusia harus saling membantu dalam segala hal dan menghindari pertengkaran. Manusia diungkapkan sebagai kupu-kupu yang bisa terbang dengan sendirinya, dengan percaya diri membawa berita kepada seluruh dunia tentang arti kehidupan. Lewat rumpaka tersebut Gugum Gumbira ingin menyampaikan kepada bapak Soeharto dan ibu Tien bahwa dalam masa pembangunan yang sedang berlangsung, bapak Soeharto dan ibu Tien harus ingat dan hati-hati dalam bersikap dan bertindak akan segala sesuatu, agar tidak terjadi pertengkaran dan perpecahan.

\section{Aspek Rias dan Busana Tari Rawayan}

Pada tari Rawayan penari menggunakan rias korektif. Rias korektif yaitu tata rias wajah yang menggunakan bahanbahan kosmetik dengan polesan yang tidak berlebihan serta bentuk alis hanya dipertebal sesuai dengan bentuk wajahnya, dalam arti kalau untuk wanita akan terlihat lebih cantik dan mempertegas bentuk garis pada bagian wajah. ${ }^{10}$ Pada bagian kepala, dipakai konde (sanggul), hiasan sanggul berbentuk daun awi

10 Indah Nuraini, Tata Rias dan Busana Wayang Orang Gaya Surakarta, Yogyakarta: Badan Penerbit ISI Yogyakarta, 2011, 45. (daun bambu) berwarna perak, serta ronce (rangkaian bunga melati). Penggunaan hiasan sanggul berbentuk daun bambu menegaskan bahwa tanaman bambu dalam setiap bagian memiliki banyak manfaat dan kegunaan. Pada bagian tunas mudanya dapat dijadikan makanan, batangnya dapat digunakan sebagai wadah memasak dan juga dapat digunakan sebagai pengganti kayu dalam membuat sarana rumah tangga, daunnya dapat berguna sebagai alat pembungkus makanan, dan akarnya dapat menjadi berbagai kerajinan. Gugum Gumbira menganalogikan sifat manusia harus berguna bagi banyak orang sama seperti tanaman bambu yang dalam setiap bagiannya dapat berguna dan memiliki manfaat.

Pada psikologi warna, perak menandakan waktu untuk refleksi dan perubahan arah sebagaimana karakteristiknya yang memberikan pantulan sinar jauh ke depan. Warna perak bersifat menenangkan dan memurnikan, maka dari itu warna perak membantu proses pembersihan dan pelepasan dari masalahyang terkait dengan mental, fisik, dan emosional, dengan karakteristiknya yang reflektif (cermin), fleksibel, dan sensitif, warna perak dipercaya sebagai cermin menuju jiwa, sehingga membantu kita melihat diri sendiri dari mata orang lain. ${ }^{11}$ Bunga melati yang digunakan pada tari Rawayan merupakan

${ }^{11} \mathrm{http}$ ://informasitips.com/arti-warna-silverperak diakses pada tanggal 12 Mei 2019 pada pukul $10.40 \mathrm{WIB}$ 
ronce (rangkaian bunga melati) yang disusun memanjang dari konde (sanggul) hingga bagian bawah dada. Letak ronce bunga melati tersebut berada di bagian sisi kiri kepala penari. Bunga melati merupakan simbol wanita yang menjunjung tradisi, menggambarkan kesucian, keanggunan, kesederhanaan, dan ketulusan.

Pada bagian busana, tari Rawayan didominasi dengan warna biru tua dan biru muda. Bagian badan memakai baju kaos lengan panjang berbahan ketat berwarna biru muda. Pada bagian luarnya diberi rompi berbahan satin berwarna biru tua berkancing belakang, bagian depan rompi diberi draperi. Bagian kaki mengenakan celana panjang berbahan ketat berwarna biru muda. Pada bagian luarnya memakai sinjang dodot yang dimodifikasi menjadi rok berbahan satin yang dirempel pada bagian bawahnya dengan warna biru tua. Pengganti selendang sekaligus ikat pinggang berwarna biru tua dan diberi renda berwarna perak. Aksesoris yang melengkapi tampilan visualnya yaitu gelang tangan berwarna perak, anting yang berwarna biru, dan kalung rantai berwarna perak. ${ }^{12}$

Gugum Gumbira menjelaskan bahwa penggunaan kaos dan celana panjang berbahan ketat pada tari Rawayan berfungsi untuk mempermudah penari dalam bergerak, seperti

${ }^{12}$ Wawancara dengan Miya Rumiyana Soelandjana, perancang rias busana tari Rawayan, tanggal 6 Mei 2019. Diizinkan untuk dikutip. pohon bambu yang kokoh namun memiliki unsur elastisitas. Dari wawancara dengan Miya Rumiyana Soelandjana sebagai penata rias busana tari Rawayan, didapatkan data bahwa Gugum Gumbira tidak mengaitkan penggunaan kaos dan celana panjang berbahan ketat ini kepada unsur keagamaan atau unsur lainnya. Gugum Gumbira hanya ingin melihat penarinya bergerak dengan bebas dan leluasa tanpa harus memikirkan bentuk busana yang rumit. ${ }^{13}$

Pada psikologi warna biru umumnya memberikan efek menenangkan dan diyakini mampu mengatasi kecemasan serta merangsang pemikiran yang jernih. ${ }^{14}$ Gugum Gumbira menjelaskan bahwa pada kostum tari Rawayan didominasi oleh warna biru karena Gugum Gumbira ingin warna biru itu memberikan aura kelembutan, ketenangan, kedamaian, keikhlasan yang mengingatkan kita untuk bersikap lembut, tenang, damai, dan ikhlas dalam menghadapi kehidupan.

${ }^{13}$ Wawancara dengan Miya Rumiyana Soelandjana, perancang rias busana tari Rawayan, tanggal 6 Mei 2019. Diizinkan untuk dikutip.

${ }^{14} \mathrm{https}: / /$ goodminds.id/arti-warna/ diakses pada tanggal 12 Mei 2019 pada pukul 11.28 WIB. 


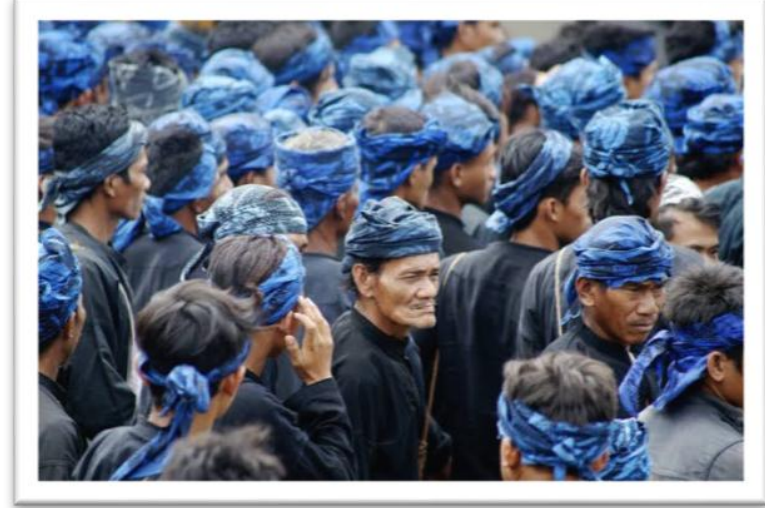

Gambar 5: Mayarakat Suku Baduy Luar (Berbaju Hitam Dengan Ikat Kepala Berwarna Biru).

Sumber:

http://www.mongabay.co.id/2018/04/25/begini -meriahnya-serba-baduy-ritual-syukurmasyarakat-baduy/ diakses pada tanggal 13 Mei 2019 pada pukul 17.57 WIB.

Penggunaan warna biru juga dipilih karena warna biru merupakan warna kain khas Suku Baduy Luar. Laki-laki Suku Baduy Luar menggunakan kain bermotif khas mereka sebagai ikat kepala, sedangkan kaum perempuan menggunakan kain bermotif khas mereka pada sinjang (rok). Warna biru sendiri menurut suku Baduy seperti warna langit, memiliki arti keteguhan, ketenangan, kemenangan, dan kesucian. Gugum Gumbira berharap dengan tari Rawayan yang rias busananya warna biru dapat menyampaikan makna untuk bersama-sama hidup menuju titik yang lebih baik dan menjadi pribadi yang tangguh.

Busana tari Rawayan tidak banyak berubah dari tahun petama kali dipentaskan di tahun 1986 hingga saat ini. Hal tersebut membuktikan bahwa tari Rawayan memiliki sejarah yang sangat berharga bagi Gugum Gumbira, Padepokan Jugala, serta pihak-pihak yang terlibat dalam penciptaan tari Rawayan sehingga dapat dilihat tidak terdapat pembaharuan yang terjadi pada tari Rawayan sejak pertama kali dipentaskan hingga saat ini karena Gugum Gumbira ingin menjaga orisinalitas tari Rawayan.

\section{PENUTUP}

Tari Rawayan merupakan sebuah tari Jaipongan karya Gugum Gumbira yang syarat akan makna simbolis yang terkandung di dalamnya. Makna yang terkandung tersebut, menggambarkan bagaimana cara menyikapi kehidupan yang hanya penuh dengan kefanaan. Setiap manusia yang hidup di dunia ini seperti layaknya wayang yang dimainkan oleh sang dalang atau Tuhan Yang Maha Esa. Manusia tidak memiliki daya upaya atau kekuatan yang mampu menandingi kuasa-Nya. Hendaknya setiap manusia yang hidup di dunia harus berhati-hati dalam melangkah dan bertindak, bila tidak nafsulah yang akan membuat diri menyesal.

Tari Rawayan memiliki keterkaitan khusus dengan masyarakat Suku Baduy Luar. Kata Rawayan dalam bahasa Sunda memiliki arti jembatan yang terbuat dari bambu. Rawayan terdapat di Kampung Gajeboh, Desa Kanekes, Kabupaten Lebak, Banten, Jawa 
Barat. Korelasi antara judul tari dengan tema tari Rawayan adalah disaat menyebrangi rawayan, kita harus berhati-hati dalam melangkah. Hal tersebut Gugum Gumbira analogikan dengan situasi yang terjadi pada masa pembangunan yang diusung bapak Soeharto dan ibu Tien. Ia ingin menyampaikan bahwa dalam masa pembangunan yang sedang berlangsung ini, bapak Soeharto dan ibu Tien harus ingat dan hati-hati dalam mempertahankan nilai-nilai tradisi yang dimiliki bangsa Indonesia agar tercapainya kestabilan yang merupakan persyaratan agar pembangunan dapat berlangsung dengan baik. Hal tersebut bukan hanya wejangan untuk bapak Soeharto dan ibu Tien Soeharto melainkan untuk seluruh manusia yang hidup di bumi ini.

Tari Rawayan merupakan sebuah tarian yang tampaknya sederhana namun di balik kesederhanaannya memiliki nilai yang sangat tinggi. Nilai tinggi yang dimiliki tari Rawayan bukan hanya karena tarian ini tercipta atas permintaan Ibu Negara Republik Indonesia pada saat itu yaitu Ibu Tien Soeharto, melainkan nilai yang tinggi tersebut muncul dari makna dan simbol yang Gugum Gumbira tuangkan pada tari Rawayan tersebut. Tema tari Rawayan yang mencerminkan kehatihatian yang meliputi segala aspek kehidupan yang dijalani manusia merupakan ilmu yang sangat berguna bagi penikmat seni yang tidak hanya melihat sisi teks suatu karya tari melainkan melihat juga sisi konteks dari karya tari tersebut.

Tari Rawayan pantas dijadikan panutan sikap yang baik bagi masyarakat yang beretnis Sunda sendiri maupun masyarakat di luar etnis Sunda, karena tari Rawayan merupakan sebuah tarian yang memvisualisasikan citra perempuan khususnya perempuan khususnya perempuan Sunda yang pemberani, tangguh, tegas, percaya diri, bertanggungjawab, memiliki tingkat kewaspadaan yang tinggi dan memiliki rasa mengayomi atau kekeluargaan. Tari Rawayan dapat dijadikan simbol perempuan Sunda yang memiliki dua sisi yang berbeda namun saling berhubungan yaitu sisi lemah lembut dan sisi tangguh yang diperlukan dalam menjalani kehidupan. Tari Rawayan menyimbolkan perempuan Sunda yang sederhana, cantik apa adanya tidak cantik dari sesuatu yang membalut dirinya seperti emas dan permata namun karena kecantikan yang terpancar dari hatinya, mandiri, dapat menjadi tulang punggung keluarga, dan dihormati di lingkungan sekitarnya.

Tari Rawayan dapat menjadi tontonan serta tuntunan dan diminati sebagai pembelajaran pelestarian kesenian khususnya pada bidang seni tari oleh masyarakat khususnya masyarakat Jawa Barat dan masyarakat di luar Jawa Barat. Gugum 
Gumbira sebagai pencipta tari Rawayan bersama tim Padepokan Jugala semestinya lebih genjar membuat workshop tari Rawayan karena tari Rawayan ini selain memiliki nilai yang baik dalam unsur visualnya, tari Rawayan juga memiliki nilai yang baik dalam konteks makna dan simbol yang terkandung dalam setiap aspek yang dimilikinya. Tari Rawayan dapat menjadi pengingat bahwasanya dalam memimpin negara yang besar ini dibutuhkan pribadi-pribadi yang senantiasa berhati-hati bertindak dan berucap agar terjalinnya keharmonisan yang merupakan tujuan dan cita-cita seluruh masyarakat suatu negara.

\section{DAFTAR SUMBER ACUAN}

A. Sumber Tercetak

Aziz, Herdiani, Rusliana dkk. Ed. Endang Caturwati dan Lalan Ramlan. 2007. Gugum Gumbira dari ChaCha ke Jaipongan. Bandung: Sunan Ambu Press - STSI Bandung.

Artha, Arwan Tuti. 2007. Bu Tien Wangsit Keprabon Soeharto. Yogyakarta: Galangpress.

Caturawati, Herdiani, Sudjana dkk. Ed. F.X Widaryanato dan Endang Caturwati. 2003. Lokalitas, Gender, dan Seni Pertunjukan di Jawa Barat. Yogyakarta: Aksara Indonesia.

Dillistone, F.W. 1986. The Power of Symbols. Terj. A. Widyamartaya. 2002. Daya Kekuatan Simbol. Yogyakarta: Kanisius.
E. Palmer, Richard. 1969. Hermeneutics: Interpretation Theory in Schleirmacher, Dilthey, Heidegger, and Gadamer. Terj. Musnur dan Damanhuri Muhammed. 2005. Hermeneutika: Teori Baru Mengenai Interpretasi. Yogyakarta: Pustaka Pelajar.

Ekadjati, Edi S. 1984. Masyarakat Sunda dan Kebudayaannya. Jakarta: Girimukti Pasaka.

Ekadjati, Edi S. 2009. Kebudayaan Sunda Suatu Pendekatan Sejarah. Jakarta: PT Dunia Pustaka.

Fay, Brian. 1998. Contemporary Philosophy of Social Science. Terj. M. Muhith. 2002. Filsafat Ilmu Sosial Kontemporer. Yogyakarta: Penerbit Jendela.

Hadi, Y. Sumandiyo. 2007. Kajian Tari Teks dan Konteks. Yogyakarta: Pustaka Book Publisher bekerjasama dengan Jurusan Seni Tari Press FSP, ISI Yogyakarta.

Hadi, Y. Sumandiyo. 2014. Koreografi (Bentuk-Teknik - Isi). Yogyakarta: Cipta Media.

Hadi, Y. Sumandiyo. 2017. Koreografi Ruang Prosenium. Yogyakarta: Cipta Media.

Hellwig, Jean. 1993. Performance in Java and Bali: Studies of Narrative, Theater, Music, and Dance. Ed. Bernard Arps. London: University of London, School of Oriental and African Studies.

Irdawati, 2013. Spektrum Tari Toga: Dari Legenda ke Notasi Laban. Yogyakarta: Media Kreativa. 
Knapp, Retnowati Abdulgani. 2007. Soeharto the Life and Legacy of Indonesian's Second President. Jakarta: Kata Hasta Pustaka.

Lubis, Nina Herlina. 1998. Kehidupan Kaum Menak Priangan 1800-1942. Bandung: Pusat Informasi Kebudayaan Sunda.

Lubis, Nina Herlina. 2016. Sejarah Kota Bandung. Bandung: Pemerintah Kota Bandung.

Narawati, Tati. 2003. Wajah Tari Sunda dari Masa ke Masa. Bandung: P4ST Universitas Pendidikan Indonesia.

Nuraini, Indah. 2011. Tata Rias dan Busana Wayang Orang Gaya Surakarta. Yogyakarta: Badan Penerbit ISI Yogyakarta.

Ramlan, Lalan. 2013. "Jaipongan: Genre Tari Generasi Ketiga dalam Perkembangan Seni Pertunjukan Tari Sunda". Jurnal Resital, Vol. 14 ,No. 1, Juni, Yogyakarta, 41.

Ratna, Nyoman Kutha. 2015. Estetika Sastra dan Budaya. Yogyakarta: Pustaka Pelajar.

Robinson, Richard. 1986. Indonesian : The Rise of Capital. Terj. Harsutejo. 2012. Soeharto \& Bangkitnya Kapitalisme Indonesia. Jakarta: Komunitas Bambu.

Rusmana, Dadan. 2014. Filsafat Semiotika Paradigma, Teori, dan Metode Intepretasi Tanda dari Semiotika Struktural Hingga Dekonstruksi. Bandung: CV Pustaka Setia.

S. Kosoh, Suwarno K, Syafei. 1979. Sejarah Daerah Jawa Barat.
Jakarta: Proyek Penerbitan Buku Bacaan dan Sastra Indonesia dan Daerah.

Saepudin, Asep. 2013. Garap Tepak Kendang Jaipongan Dalam Karawitan Sunda. Yogyakarta: BP ISI Yogyakarta.

Saepudin, Asep. 2015. Metode Pembelajaran Tepak Kendang Jaipongan. Yogyakarta: BP ISI Yogyakarta.

Simatupang, Lono. 2013. Pergelaran Sebuah Mozaik Penelitian Seni Budaya. Yogyakarta: Jalasutra.

Sobur, Alex. 2015. Analisis Teks Media Suatu Pengantar untuk Analisis Wacana, Analisis Semiotik, dan Analisis Framing. Bandung: PT Remaja Rosdakarya.

Suganda, Her. 2007. Jendela Bandung: Pengalaman Bersama Kompas. Jakarta: Kompas.

Sumardjo, Jakob. 2011. Pola Rasionalitas Budaya. Bandung: Kelir.

Sumardjo, Jakob. 2014. Estetika Paradoks. Bandung: Kelir.

Sumaryono. 2014. Karawitan Tari Suatu Analisis Tata Hubungan. Yogyakarta: Cipta Media.

Sumaryono. 2017. Antropologi Tari dalam Perspektif Indonesia. Yogyakarta: Media Kreatifa.

Sumaryono, E. 1999. Hermeneutik Sebuah Metode Filsafat. Yogyakarta: Kanisius.

B. Narasumber: 


\section{JOGED}

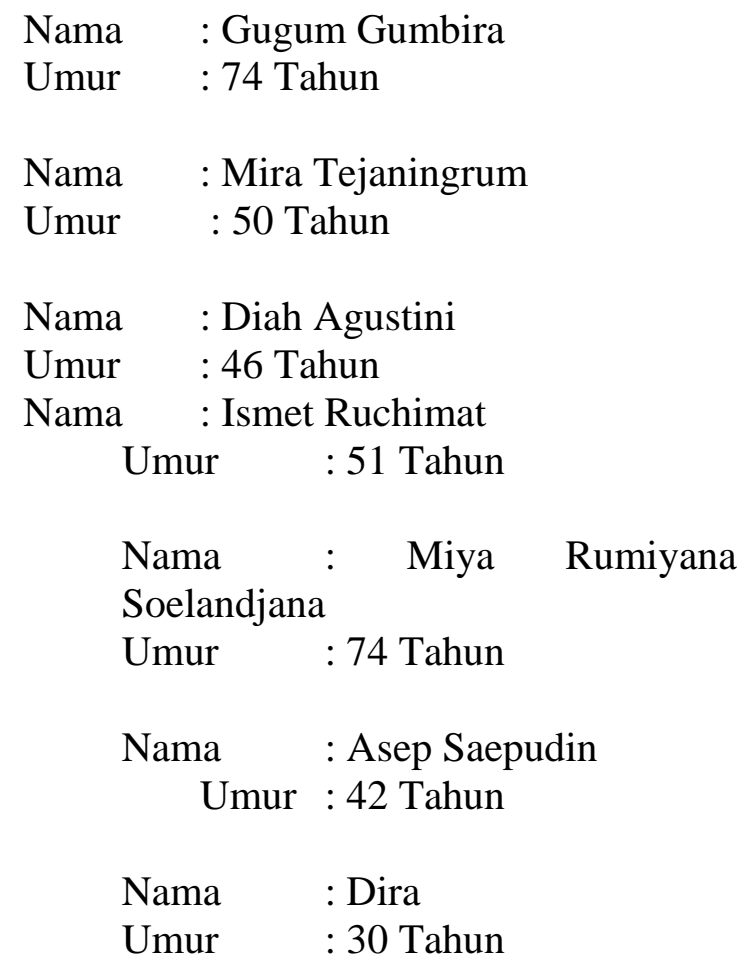

C. Diskografi

https://doksen.isbi.ac.id/index.php/v ideo/video-fsp/video-tari/video/tarirawayan. Video tari Rawayan yang merupakan video Ujian Tugas Akhir Gel 1. Fakultas Seni Pertunjukan Prodi Seni Tari ISBI Bandung Tahun 2017 oleh Mella Restuaffina. Diakses pada tanggal 20 Mei 2019.

https://www.google.com/url?sa+t\&s ource+web\&rct $+j \&$ url $+\% 23 \&$ ved $=0$ ahUKEwjx36KXrqjiAhUN4o8KHS p3Db8Qxa8BCCgwAQ\&usg. Video tari Rawayan yang merupakan video Ujian Tugas Akhir Prodi Seni Tari SMKN 10 Bandung Tahun 2015 oleh Elma Merdiana. Diakses pada tanggal 20 Mei 2019.

https://www.google.com/url?sa=t\&s ource $=$ web \&rct $=j \&$ url $=\% 23 \&$ ved $=0$ ahUKWwjJq8ru8LTjAhU07nMBHe WiB9QQxa8BCDkwCQ\&usg.

Video tari Rawayan yang merupakan video Pasanggiri Jaipongan Jugala Raya 2013 se-
Jawa Barat yang dipublish oleh Aki Anom. Diakses pada tanggal $20 \mathrm{Mei}$ 2019.

D. Webtografi

https://budaya-indonesia.org/TariJaipongan-Rawayan

repository.upi.edu/20264/. 